\title{
A critique of fluid bolus resuscitation in severe sepsis
}

\author{
Andrew K Hilton ${ }^{1}$ and Rinaldo Bellomo ${ }^{2 *}$
}

\begin{abstract}
Resuscitation of septic patients by means of one or more fluid boluses is recommended by guidelines from multiple relevant organizations and as a component of surviving sepsis campaigns. The technique is considered a key and life-saving intervention during the initial treatment of severe sepsis in children and adults. Such recommendations, however, are only based on expert opinion and lack adequate experimental or controlled human evidence. Despite these limitations, fluid bolus therapy (20 to $40 \mathrm{ml}$ / $\mathrm{kg}$ ) is widely practiced and is currently considered a cornerstone of the management of sepsis. In this pointof-view critique, we will argue that such therapy has weak physiological support, has limited experimental support, and is at odds with emerging observational data in several subgroups of critically ill patients or those having major abdominal surgery. Finally, we will argue that this paradigm is now challenged by the findings of a large randomized controlled trial in septic children. In the present article, we contend that the concept of large fluid bolus resuscitation in sepsis needs to be investigated further.
\end{abstract}

The difficulty lies, not in new ideas, but in escaping old ones, which ramify, for those brought up with them, as most of us have been, into every corner of our minds.

John Maynard Keynes

If a clinician investigator enters the terms 'sepsis' AND 'fluid resuscitation' AND 'humans' AND 'clinical trials' into the PubMed electronic reference library system, he or she should be able to identify 84 publications. This

*Correspondence: rinaldo.bellomo@austin.org.au

${ }^{2}$ Australian and New Zealand Intensive Care Research Centre, School of Public Health and Preventive Medicine, Monash University, Alfred Centre, Commercial Road, Prahran, Melbourne, Victoria 3181, Australia

Full list of author information is available at the end of the article result might initially suggest that there is a treasure trove of experimentally robust evidence to guide clinicians in this field and support the notion that fluid resuscitation leads to better outcomes in septic patients. When the search is narrowed to randomized controlled trials, however, the list rapidly shortens to 47 papers - and disappointment sets in when these studies are analyzed in detail, as only two papers remain that use more than physiological outcomes as end points [1,2]. As of 25 May 2011, no studies existed comparing the initial resuscitation of patients with sepsis or septic shock with fluid boluses versus no fluid boluses; or indeed comparing large fluid boluses with moderate fluid boluses combined with vasopressor drugs. Finally, the only multicentre randomized controlled studies available were designed to address the type of fluids to be used for such resuscitation $[1,2]$, not whether the fluids should have been given in the first place. Additionally, only two studies report data on mortality [1,2]. Most of the human studies available focus on the physiological effects of fluid boluses [3-5] rather than on patient-centered outcomes.

Despite the limited evidence, such is the hold of the fluid bolus resuscitation paradigm on the mind of critical care physicians that no one has ever considered challenging this prevailing dogma. Now that the FEAST study has created such a challenge [6], it seems important to reflect on why we believe fluid bolus resuscitation should be a cornerstone of the management of severe sepsis or septic shock.

\section{The philosophical fallacy: bolus fluid resuscitation is self-evidently beneficial}

When fluid boluses are given to septic patients, clinicians are typically confronted with an unwell, hypotensive patient. The low blood pressure is often associated with an increased blood lactate concentration, a low urinary output, and other signs and symptoms of physiological distress. Clinicians then make a compelling pathophysiological inference and reason that there must be inadequate vital organ blood flow (typically described by the loose term perfusion) to explain this clinical picture. This inference is necessary because vital organ blood flow cannot be accurately measured in acutely septic patients. 
An additional inference is then made that that the patient's cardiac output must be low because the vasodilatation, which is responsible for the patient's low blood pressure, must have decreased venous return and thereby preload. This is despite the fact that no multicenter case series exists to demonstrate in unresuscitated sepsis that the cardiac output is typically below the normal reference range. Nonetheless, once these inferences are made, then rapid bolus fluid resuscitation becomes physiologically logical and the need for its administration becomes self-evident. Such fluid bolus becomes the best means by which cardiac output can be increased, organ blood flow restored and arterial blood pressure improved.

The above paradigm rests, of course, on the untested assumption that the above increases are both necessary and life-saving and that using vasopressor drugs or moderate fluid therapy with vasopressor drugs to achieve them would lead to inferior patient outcomes. We can find no evidence of consideration being given to the concept that increasing the delivery of cytokine-rich, potentially toxic blood to the organs may, in fact, be deleterious and increase the statistical risk of immunemediated organ injury and failure. Similarly, we can find no evidence of consideration being given to the possibility that, to a degree, this hypotensive state may have evolved as a protective mechanism through millions of years of mammalian evolution and that therefore caution should be applied when administering therapies such as intravenous fluid boluses that have not been part of such an evolutionary armamentarium.

Given this loose construction of post hoc inferences and teleological argument, many fundamental questions require an answer. For example, does fluid bolus resuscitation in patients with severe sepsis actually increase vital organ blood flow or even cardiac output? If it does, what is the magnitude of its effect on both the blood flow and cardiac output for a given dose? How long does this effect last? What is the physiological price (positive fluid balance, worse gas exchange, organ edema, acid-base changes) paid to achieve this effect? What evidence do we have to answer some of these questions in man?

Unfortunately, there are no convincing answers to any of the above questions. No human studies have measured cardiac output at presentation to the emergency department in septic patients before and after fluid resuscitation, let alone made attempts to measure vital organ blood flow. No human studies have measured how much such cardiac output increases when a recommended fluid bolus [7-9] of 20 to $30 \mathrm{ml} / \mathrm{kg}$ over 30 to 60 minutes is given. No human studies have reported how long such an increase might last. No human studies have reported the magnitude and duration of the effect of fluid bolus resuscitation on the mean arterial blood pressure, and so on (the fact that many of these patients are admitted to intensive care to receive vasopressor therapy must, at the very least, imply that fluid boluses do not reliably restore target blood pressure). Additionally, no human studies have measured what happens to organ blood flow (perfusion) before and immediately after fluid bolus resuscitation. Finally, until recently, no study had asked the ultimate question: are the physiological gains (if they exist) worth the physiological costs (as listed above)? We now know that the answer in children in resource-poor countries is a resounding 'no'. It seems open to question that a therapy associated with close to a $50 \%$ increase in the risk of death in African children would instead decrease the risk of death in adults in resource-rich countries instead.

\section{The experimental fallacy: animal experiments prove it}

Sometimes interventions cannot be easily studied in a controlled fashion in humans. Animal experiments then provide the only scientific knowledge that guides clinical practice.

In this field one might reasonably expect a large body of research to consistently show that fluid resuscitation increases survival in models of sepsis compared with no fluid resuscitation. In fact, if the clinician investigator using the above search terms applied to human studies now confined them to animal studies, he or she would find 284 papers. Unfortunately, however, of these only four assess the impact of fluid bolus resuscitation compared with no fluid bolus resuscitation or limited fluid therapy on mortality.

One study in 90 mice found increased survival with fluid bolus resuscitation [10]; another study in rats also found improved survival [11]. A third study in 48 pigs compared fixed moderate fluid resuscitation $(10 \mathrm{ml} / \mathrm{kg})$ with higher volume fluid resuscitation $(20 \mathrm{ml} / \mathrm{kg})$, accompanied by boluses of $50 \mathrm{ml}$ hydroxyethyl starch in response to low cardiac filling pressures and/or oliguria. This study found increased mortality in animals allocated to fixed higher volume resuscitation [12]. A fourth study in mice also found that fluid therapy increased survival compared with control. However, such therapy was given as subcutaneous boluses every 6 hours, making inferences concerning intravenous fluid boluses in human sepsis problematic [13]. This level of experimental evidence is hardly overwhelming.

Yet, one might argue - if experimental evidence showed that septic models typically, consistently and reliably induce a low cardiac output, low organ blood flow state - that such evidence might be enough to justify our inferences about humans and fluid bolus therapy. Unfortunately, this is not the case because several models show the opposite (high cardiac output and increased 
organ blood flow) [12-15]. Moreover, even in severe septic shock, magnetic resonance technology demonstrates continued preservation of renal ATP [16], suggesting no bio-energetic deficit to justify the need for increased perfusion. Yet even if this was the case, evidence in normal and septic animals that fluid therapy consistently leads to major $(>50 \%)$ and sustained (hours to days) increases in organ blood flow would surely provide some justification for fluid boluses in sepsis. Unfortunately, animal studies show that the effects of bolus fluid resuscitation typically dissipate within 45 to 60 minutes for crystalloids and somewhat longer for colloids $[17,18]$. What should one then do for the next 23 hours? Repeat the bolus every hour until the patient is 10 liters of fluid overloaded? Given the association between a positive fluid balance and increased mortality in critically ill patients with sepsis and acute kidney injury [19], or with sepsis and acute respiratory distress syndrome (ARDS) [20], this approach seems illogical and possibly dangerous [21].

\section{The analogy fallacy: we should give fluids because they help in other conditions}

Although there are no controlled human studies supporting fluid bolus resuscitation in sepsis and there are also no convincing supportive animal studies, clinicians could justify such treatment by analogy: fluid resuscitation makes other really sick patients better, so it should make septic patients better too. This argument appears to have merit as it seems self-evident that fluid therapy has saved and still saves millions of patients with cholera and other forms of bacterial or viral diarrhea leading to severe fluid depletion. Yet these patients have clearly lost large amounts of isotonic fluids and the analogy argument stops right there. Fluid resuscitation, on the other hand, worsens outcomes in bleeding patients with penetrating torso injury [22], positive fluid balances increase morbidity in patients with acute kidney injury [19] and ARDS [20], and fluid liberal approaches increase morbidity in patients receiving colorectal surgery [23]. Once again, this is not exactly overwhelming evidence that fluid boluses in sepsis are clearly justified, even by analogy with other, similar, medical conditions.

\section{The phenotype fallacy: the abiding power of association}

Perhaps the strongest driver to fluid bolus resuscitation in sepsis has been the association between a hyperdynamic cardiac output state and better outcome in patients with critical illness [24]. This association has led people to believe that, if only we could change patients with a normal cardiac output or a low-normal cardiac output or a minimally increased cardiac output into patients with a markedly hyperdynamic (high or very high cardiac output) circulation, just like the patients who seem to do better, then all would be well. This notion has been challenged by multiple studies showing that increasing cardiac output or mixed venous oxygen saturation with or without fluids or inotropic drugs does not achieve improved outcomes and may in fact worsen them $[25,26]$.

Moreover, it is a formal logical fallacy to reason that 'survivors have a hyperdynamic circulation; therefore, if a patient can be made to have a hyperdynamic circulation, he or she will survive'. It is also a pathophysiological fallacy that one can take patients with a hemodynamic phenotype associated with a statistically less favorable outcome and, with fluid loading or inotropic drugs or both, change them into the cardiovascular phenotype of those patients who seem to do better and then expect such patients to achieve better survival. There are several potential reasons why these patients display a nonhyperdynamic phenotype in the first place (underlying co-morbidities, different physiological reserve, different bacterial load, different genetically-driven responses, and so on). These forces are the likely major drivers of their outcome. Changing one aspect (cardiac output) of their phenotype with fluids will not alter these driving forces and is unlikely to alter prognosis. To use an analogy: repainting the façade of a crumbling building will no doubt change its 'phenotype', but the building will still collapse.

\section{Where are we now?}

So, up to 26 May 2011, we had no controlled human data and no understanding of the physiological effects of fluid bolus resuscitation in humans presenting with severe sepsis compared with just simple fluid replacement therapy. Instead, we used untested inferences, had patchy and contradictory animal data, relied on weak clinical analogies and were enticed by the phenotype association fallacy. Such a situation alone should have demanded a serious reassessment of our faith in fluid boluses for the resuscitation of septic patients anyway.

Now, however, we have a large randomized controlled trial in more than 3,000 subjects (children) with no comorbidities and no artificial confounders (rescue mechanical ventilation, rescue vasopressor therapy, rescue dialysis, rescue extracorporeal membrane oxygenation) [6]. This trial found that saline or albumin fluid resuscitation increased mortality by almost $50 \%$. The study has many strengths, but it also has many characteristics that make it open to criticism in terms of its relevance to patients seen in resource-rich countries. Key concerns are that only a minority of children had severe hypotension and all such severely hypotensive children received fluid bolus resuscitation; one-third of children had hemoglobin $<5 \mathrm{~g} / \mathrm{dl}$, suggesting that fluid-induced hemodilution in itself is dangerous; and $80 \%$ had respiratory distress, making fluid loading particularly 
problematic in the absence of rescue mechanical ventilation. These observations make these patients perhaps more closely related to those in the FACTT study, where fluids were shown to adversely affect the outcome of patients with the combination of ARDS and sepsis [20]. Their relevance to septic patients presenting to emergency departments of resource-rich countries is therefore also open to challenge.

These concerns highlight the fact that one should be cautious in using this FEAST trial as a clear-cut analogy for how sepsis resuscitation should be managed in resource-rich countries. Given the findings and limitations of the FEAST study, however, and the context discussed above, it remains legitimate to ask: what is the role of fluid bolus resuscitation in human sepsis? While in resource-rich countries the above difference in mortality may almost entirely disappear as rescue therapies are applied to attenuate any potential adverse effect of fluid overload (ARDS, pulmonary edema, acute kidney injury), there is now concern that such therapy may not be as beneficial as previously believed.

Given the risks and the frequency of use, the time has come to conduct randomized controlled trials in septic children and adults in developed countries to attempt to answer this important question. Fortunately, several studies are currently underway in the USA (PROCESS), in Australia and New Zealand (ARISE), and in the United Kingdom (PROMISE) that address the issue of whether early goal-directed resuscitation increases survival in severe sepsis. These and other such studies will also provide crucial information on the association between fluid bolus resuscitation and outcome, and will be an important additional step in the reassessment of this therapy.

In the meanwhile, the authors believe that a moderate position might be reasonable until further information is available. The treatment of patients with severe sepsis/ septic shock in resource-rich countries need not yet change. While clinicians in developed countries are unlikely to ever consider managing these patients without fluid resuscitation, however, it is likely that there will be renewed interest in applying a strategy that moderates the amount of fluid given to perhaps 20 to $25 \mathrm{ml} / \mathrm{kg}$ over the first 6 hours and promotes the earlier use of vasopressor drugs. This approach to resuscitation is already widespread in Australia and New Zealand [27] and is associated with excellent outcomes.

\section{Abbreviations}

ARDS, acute respiratory distress syndrome.

\section{Competing interests}

The authors declare that they have no competing interests.

\section{Author details}

'Department of Intensive Care, Alfred Hospital, Commercial Road, Prahran, Melbourne, Victoria 3181, Australia. ${ }^{2}$ Australian and New Zealand Intensive
Care Research Centre, School of Public Health and Preventive Medicine, Monash University, Alfred Centre, Commercial Road, Prahran, Melbourne, Victoria 3181, Australia.

Published: 25 January 2012

\section{References}

1. SAFE Study Investigators: Impact of albumin compared to saline on organ function and mortality of patients with severe sepsis. Intensive Care Med 2011, 37:86-96.

2. Brunkhorst FM, Engel C, Bloos F, Meier-Hellmann A, Ragaller M, Weiler N, Moerer O, Gruendling M, Oppert M, Grond S, Olthoff D, Jaschinski U, John S, Rossaint R, Welte T, Schaefer M, Kern P, Kuhnt E, Kiehntopf M, Hartog C, Natanson C, Loeffler M, Reinhart K; German Competence Network Sepsis (SepNet): Intensive insulin therapy and pentastarch resuscitation in severe sepsis. N Engl J Med 2008, 358:125-139.

3. Friedman G, Jankowski S, Shahla M, Gomez J, Vincent JL: Hemodynamic effect of $6 \%$ and $10 \%$ hydroxyethyl starch solutions versus $4 \%$ albumin solution in septic patients. J Clin Anesth 2008, 20:528-533.

4. Fang ZX, Li YF, Zhou XQ, Zhang Z, Zhang JS, Xia HM, Xing GP, Shu WP, Shen L, Yin GQ: Effects of resuscitation with crystalloud fluids on cardiac function in patients with severe sepsis. BMC Infect Dis 2008, 8:50.

5. Molnar Z, Mikor A, Leiner T, Szakmany T: Fluid resuscitation with colloids of different molecular weight in septic shock. Intensive Care Med 2004, 30:1356-1360.

6. Maitland K, Kiguli S, Opoka RO, Engoru C, Olupot-Olupot P, Akech SO, Nyeko R, Mtove G, Reyburn H, Lang T, Brent B, Evans JA, Tibenderana JK, Crawley J, Russell EC, Levin M, Babiker AG, Gibb DM; FEAST Trial Group: Mortality after fluid bolus in African children with severe infection. NEngl J Med 2011, 364:2483-2495.

7. Brierley J, Carcillo JA, Choong K, Cornell T, Decaen A, Deymann A, Doctor A, Davis A, Duff J, Dugas MA, Duncan A, Evans B, Feldman J, Felmet K, Fisher G, Frankel L, Jeffries H, Greenwald B, Gutierrez J, Hall M, Han YY, Hanson J, Hazelzet J, Hernan L, Kiff J, Kissoon N, Kon A, Irazuzta J, Lin J, Lorts A, et al.: Clinical practice parameters for hemodynamic support of pediatric and neonatal septic shock: 2007 update from the American College of Critical Care Medicine. Crit Care Med 2009, 37:666-688.

8. Dellinger RP, Levy MM, Carlet JM, Bion J, Parker MM, Jaeschke R, Reinhart K, Angus DC, Brun-Buisson C, Beale R, Calandra T, Dhainaut JF, Gerlach H, Harvey M, Marini JJ, Marshall J, Ranieri M, Ramsay G, Sevransky J, Thompson BT, Townsend S, Vender JS, Zimmerman JL, Vincent JL: Surviving Sepsis Campaign: international guidelines for management of severe sepsis and septic shock: 2008. Crit Care Med 2008, 36:296-327.

9. Rivers E, Nguyen B, Havstad S, Ressler J, Muzzin A, Knoblich B, Peterson E, Tomlanovich M; Early Goal-Directed Therapy Collaborative Group: Early goal directed therapy in the treatment of severe sepsis and septic shock. NEngl J Med 2001, 345:1368-1377.

10. Zanotti-Cavazzoni SL, Guglielmi M, Parrillo JE, Walker T, Dellinger RP, Hollenberg SM: Fluid resuscitation influences cardiovascular performance and mortality in a murine model of sepsis. Intensive Care Med 2009, 35:748-754.

11. Smith EF 3rd, Slivjak MJ, Egan JW, Gagnon R, Arleth AJ, Esser KM: Fluid resuscitation improves survival of endotoxemia or septicemic rats: possible contribution of tumour necrosis factor. Pharmacology 1993 46:254-267.

12. Brandt S, Regueira T, Bracht H, Porta F, Djafarzadeh S, Takala J, Gorrasi J, Borotto E, Krejci V, Hiltebrand LB, Bruegger LE, Beldi G, Wilkens L, Lepper PM, Kessler U, Jakob SM: Effect of fluid resuscitation on mortality and organ function in experimental sepsis models. Crit Care 2009, 13:R186.

13. Hollenberg SM, Dumasius A, Easington C, Colilla SA, Neumann A, Parrillo JE: Characterization of a hyperdynamic murine model of resuscitated sepsis using echocardiography. Am J Respir Crit Care Med 2001, 164:891-895.

14. Di Giantomasso D, May C, Bellomo R: Vital organ blood flow in hyperdynamic sepsis. Chest 2003, 124:1053-1059.

15. Langenberg C, Wan L, Egi M, May CN, Bellomo R: Renal blood flow in experimental septic acute renal failure. Kidney Int 2006, 69:1996-2002.

16. May CN, Wan L, Williams J, Wellard MR, Pell G, Langenberg C, Bellomo R: A technique for the simultaneous measurement of renal ATP, blood flow and $\mathrm{pH}$ in a large animal model of septic shock. Crit Care Resusc 2007, 9:30-33.

17. Wan $L$, Bellomo R, May $C$ : The effect of normal saline resuscitation on vital 
organ blood flow in septic sheep. Intensive Care Med 2006, 32:1238-1242.

18. Wan L, Bellomo R, May CN: A comparison of $4 \%$ succinylated gelatin solution versus normal saline in stable normovolaemic sheep: global haemodynamic, regional blood flow and oxygen delivery effects. Anaesth Intensive Care 2007, 35:924-931.

19. Payen D, de Pont AC, Sakr Y, Spies C, Reinhart K, Vincent JL; Sepsis Occurrence in Acutely III Patients (SOAP) Investigators: A positive fluid balance is associated with a worse outcome in patients with acute renal failure. Crit Care 2008, 12:R74.

20. NHLBI ARDS Clinical Trials Network: Comparison of two fluid management strategies in acute lung injury. N Engl J Med 2006, 354:2564-2575.

21. Durairaj L, Schmidt GA: Fluid therapy in resuscitated sepsis: less is more. Chest 2008, 133:252-263.

22. Bickell WH, Wall MJ Jr, Pepe PE, Martin RR, Ginger VF, Allen MK, Mattox KL: Immediate versus delayed fluid resuscitation for hypotensive patients with penetrating torso injury. N Engl J Med 1994, 331:1105-1109.

23. 23. Brandstrup B, Tønnesen H, Beier-Holgersen R, Hjortsø E, Ørding H, Lindorff-Larsen K, Rasmussen MS, Lanng C, Wallin L, Iversen LH, Gramkow CS, Okholm M, Blemmer T, Svendsen PE, Rottensten HH, Thage B, Riis J, Jeppesen IS, Teilum D, Christensen AM, Graungaard B, Pott F; Danish Study Group on Perioperative Fluid Therapy: Effects of intravenous fluid restriction on postoperative complications: comparison of two perioperative fluid regimens: a randomized assessor-blinded multicenter trial. Ann Surg 2003, 238:641-648.
24. 24. Velmahos GC, Demetriades D, Shoemaker WC, Chan LS, Tatevossian R, Wo CC, Vassiliu P, Cornwell EE 3rd, Murray JA, Roth B, Belzberg H, Asensio JA Berne TV: Endpoints of resuscitation of critically injured patients: normal or supranormal? A prospective randomized trial. Ann Surg 2000, 232:409-418.

25. 25. Gattinoni L, Brazzi L, Pelosi P, Latini R, Tognoni G, Pesenti A, Fumagalli R: A trial of goal-oriented hemodynamic therapy in critically ill patients. N Engl J Med 1995, 333:1025-1032.

26. Hayes MA, Timmins AC, Yau EH, Palazzo M, Hinds CJ, Watson D: Elevation of systemic oxygen delivery in the treatment of critically ill patients. NEngl J Med 1994, 330:1717-1722

27. 27. Peake SL, Bailey M, Bellomo R, Cameron PA, Cross A, Delaney A, Finfer S, Higgins A, Jones DA, Myburgh JA, Syres GA, Webb SA, Williams P; ARISE Investigators, for the Australian and New Zealand Intensive Care Society Clinical Trials Group: Australasian resuscitation of sepsis evaluation (ARISE): a multicentre, prospective, inception cohort study. Resuscitation 2009 80:811-818

doi:10.1186/cc11154

Cite this article as: Hilton AK, Bellomo R: A critique of fluid bolus resuscitation in severe sepsis. Critical Care 2012, 16:302. 